\title{
Efficient Metal-Free NBD-maleimide Click Reaction for the Formation of Molecular Bottlebrushes
}

\author{
Zheqi Li ${ }^{1,2}$, Wangmeng Hou ${ }^{2}$, Yuanchao Li ${ }^{2}$, Jianxiong $X u^{1 *}, Y i$ Shi $^{2 *}$, Yongming Chen $^{2 *}$
}

${ }^{1}$ Hunan Key Laboratory of Biomedical Nanomaterials and Devices, College of Life Sciences and Chemistry, Hunan University of Technology, Zhuzhou 412007, China

2 School of Materials Science and Engineering, Key Laboratory for Polymeric Composite and Functional Materials of Ministry of Education, Sun Yat-Sen University, Guangzhou 510275, China 


\section{Experimental}

Materials. 4(((Butylthio)carbonthioyl)thio)-4-cyanopentanoic acid (CBPA), 6-Maleimidocaproic acid (MCA) and 4-(2-Hydroxyethyl)-10-oxa-4-azatricyclo[5.2.1.02,6]dec-8-ene-3,5dione (Fur-Mal$\mathrm{OH})$ were prepared according to literature. ${ }^{1-3}$ 2-Hydroxyethyl acrylate (HEA, 98\%, Aladdin), Tertbutyl acrylate (tBA, 98\%, Aladdin), $N, N$-Dimethylacrylamide (DMA, 98\%, Aladdin) and $N, N$ Dimethylaminoethyl acrylate was (DMAEA, Aladdin, 98\%) were purified by distilling under reduced pressure. 2,2'-Azobisisobutyronitrile (AIBN, 98\%, Guo Yao Chemicals) was recrystallized three times from ethanol. Methyl 2-octynoate (98\%, Aladdin), dicyclopentadiene (DCPD, 90\%, Alfa-Aesar), hydroquinone (98\%, Aladdin), diisobutylaluminium hydride solution (DIBAL, 1.0 M in hexanes, Aladdin), $\mathrm{NaOH}$ (AR, Guangzhou Reagent Co., China), succinic anhydride (99\%, Aldrich), Ethanolamine (98\%, Aladdin), 1-ethyl-3-(3-dimethyllaminopropyl) carbodiimide hydrochloride (EDC $\cdot \mathrm{HCl}, 97 \%$, Aladdin), 4-dimethylaminopyridine (DMAP, 99\%, Aldrich), Poly(ethylene glycol) monomethyl ether $\left(m \mathrm{PEG}-\mathrm{OH}, M_{\mathrm{n}}=2000 \mathrm{Da}\right.$, Aladdin) were used as received. All the solvents were dried and distilled before use.

\section{Instrumental Methods.}

${ }^{1} \mathrm{H}$ nuclear magnetic resonance (NMR) spectroscopy was acquired on a Bruker AVANCE III $400 \mathrm{MHz}$ spectrometer at $25{ }^{\circ} \mathrm{C}$ using DMSO- $d_{6}$ or $\mathrm{CDCl}_{3}$ as the solvents.

The DMF size exclusion chromatography (SEC) was equipped with an Agilent 1260 Iso pump, PLgel columns $\left(10 \mu \mathrm{m}\right.$ MIXED-B, $20 \mu \mathrm{m}$ MIXED-A, $20 \mu \mathrm{m}$ MIXED-A) at $50{ }^{\circ} \mathrm{C}$ with DMF flow rate $=$ $1.00 \mathrm{~mL} \mathrm{~min}^{-1}$, an Agilent 1260 refractive-index (RI) detector, linear polystyrene (PS) standards were used for calibration.

The THF size exclusion chromatography (SEC) was equipped with an Agilent 1260 Iso pump, PLgel columns $\left(5 \mu \mathrm{m} 10^{3} \AA, 5 \mu \mathrm{m} 10^{4} \AA, 5 \mu \mathrm{m} 10^{5} \AA\right)$ at $40{ }^{\circ} \mathrm{C}$ with THF flow rate $=1.00 \mathrm{~mL}$ min- 1 , an Agilent 1260 refractive-index (RI) detector, linear polystyrene (PS) standards were used for calibration. UV-vis absorption spectra were collected on an Evolution $201 \mathrm{UV} /$ vis spectrometer with Thermo Insight software at $25^{\circ} \mathrm{C}$ with glass cuvette $(1 \mathrm{~mL}, 10 \mathrm{~mm}$ path length).

Atomic force microscopy (AFM, Bruker Multimode 8 AFM (Bruker Nano Inc.)) was used to characterize the morphological structure of molecular brushes in the tapping mode with a silicon probe. 
Samples were prepared by spin-coating $10 \mu \mathrm{L}$ of dilute solutions $\left(0.01 \mathrm{mg} / \mathrm{mL}\right.$ in $\left.\mathrm{CHCl}_{3}\right)$ on freshly cleaved mica.

Synthesis of Methyl 3-pentylbicyclo[2.2.1]hepta-2,5-diene-2-carboxylate (NBD-COMe).

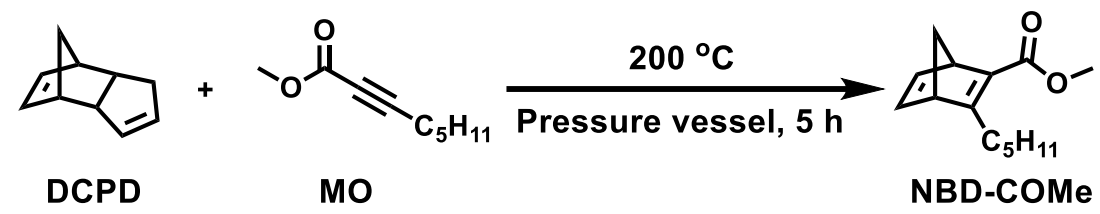

NBD-COMe was synthesized according to the literature reported by Amant et al. ${ }^{4}$ Methyl 2-octynoate (53.2 g, 0.35 mol, 1.0 eq.), dicyclopentadiene (27.3, 0.21 mol, 0.6 eq.), and hydroquinone ( $0.87 \mathrm{~g})$ were added to a pressure vessel and sealed under an atmosphere of $\mathrm{N}_{2}$. The vessel was heated to $200{ }^{\circ} \mathrm{C}$ for $5 \mathrm{~h}$. The crude product was distilled twice to afford NBD-COMe (38.6 g, 50\%) as a clear and colorless liquid.

Synthesis of (3-Pentylbicyclo[2.2.1]hepta-2,5-dien-2-yl)methanol (NBD-OH).

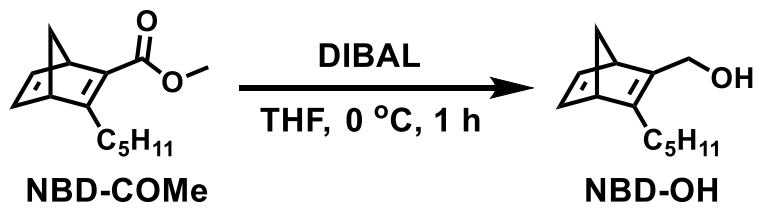

A solution of NBD-COMe (13.6 g, $62 \mathrm{mmol}, 1.0$ eq.) in THF $(450 \mathrm{~mL})$ was cooled to $0^{\circ} \mathrm{C}$, and the diisobutylaluminium hydride (DIBAL) in hexanes $(1 \mathrm{M}, 186 \mathrm{~mL}, 186 \mathrm{mmol}, 3.0$ eq.) was added dropwise over $1.5 \mathrm{~h}$. The reaction solution was maintained at $0{ }^{\circ} \mathrm{C}$ for $30 \mathrm{~min}$ and carefully quenched at $0{ }^{\circ} \mathrm{C}$ sequentially with water $(6.5 \mathrm{~mL})$, an aqueous solution of sodium hydroxide $(\mathrm{NaOH})(1 \mathrm{M}, 12.5$ $\mathrm{mL})$, and water $(6.5 \mathrm{~mL})$. The reaction mixture was allowed to be stirred at room temperature for $1 \mathrm{~h}$ before dried with $\mathrm{MgSO}_{4}$. The solvent was removed and the residue subjected to column chromatography (hexane: ethyl acetate, $3: 1)$ to yield NBD-OH (8.47 g, 71\%) as a clear and colorless oil.

Synthesis of 4-oxo-4-((3-Pentylbicyclo[2.2.1]hepta-2,5-dien-2-yl)methoxy)butanoic acid (NBDCOOH).

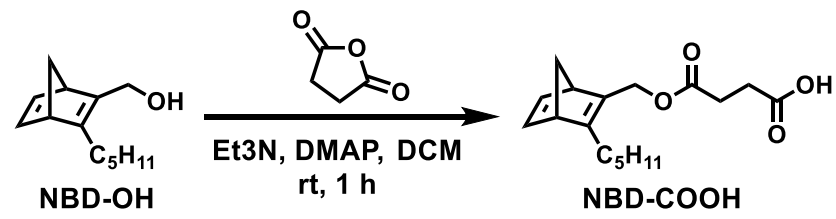


NBD-COOH was synthesized according to the literature reported by Bailey et al. ${ }^{5}$ NBD-OH $(4.81 \mathrm{~g}$, $25.0 \mathrm{mmol}, 1.0 \mathrm{eq})$ was added in dichloromethane (DCM) $(12 \mathrm{~mL})$. To the solution was added triethyl amine (2.53 mL, $25.0 \mathrm{mmol}, 1.0 \mathrm{eq}$ ), 4-dimethylaminopyridine (305 mg, $2.50 \mathrm{mmol}, 0.1 \mathrm{eq}$ ), and succinic anhydride (3.25 g, $32.5 \mathrm{mmol}, 1.3 \mathrm{eq})$. The reaction was stirred at RT under an atmosphere of air for $1 \mathrm{~h}$. The solution was transferred to a separatory funnel along with additional DCM (350 mL). The organic layer was washed with aqueous $\mathrm{HCl}(1 \mathrm{M}, 2 \times 350 \mathrm{~mL})$ then water $(350 \mathrm{~mL})$, dried over $\mathrm{MgSO}_{4}$, and the solvent removed to afford NBD-COOH (7.23 g, $\left.24.7 \mathrm{mmol}, 99 \%\right)$ of viscous oil that solidifies upon refrigeration.

\section{Synthesis of PHEA-NBD backbones.}

PHEA-NBD was obtained by a two-step way. Firstly, PHEA with different DPs were prepared by RAFT polymerization. Typical procedures in the polymerization of HEA monomer using molar ratios of $[\mathrm{HEA}]_{0}:[\mathrm{CBPA}]_{0}:[\mathrm{AIBN}]_{0}=200: 1: 0.1$ are described. HEA (3.25 g, $\left.28.0 \mathrm{mmol}\right), \mathrm{CBPA}(40.8$ mg, $0.14 \mathrm{mmol})$, AIBN (2.3 mg, $0.014 \mathrm{mmol})$ and dry DMF (3.25 g) were added into a Schlenk tube. The mixture was degassed by three freeze-evacuate-thaw cycles and the tube was sealed. The reaction was carried out at $60^{\circ} \mathrm{C}$ in $4 \mathrm{~h}$. The mixture was cooled to room temperature and exposed to air. The resulting crude product was then precipitated into a large amount of diethyl ether for three times. The precipitate was dried under vacuum. The synthesis of PHEA with DP of 210 and 419 are the same as above, but the different initial feed ratio.

Secondly, the resulted PHEA(0.60 g, $4.5 \mathrm{mmol}$ of hydroxyl groups), EDC (2.57 g, $13.4 \mathrm{mmol})$, DMAP $(0.27 \mathrm{~g}, 2.2 \mathrm{mmol})$ were dissolved in $50 \mathrm{~mL}$ dry DMF and the flask was cooled to $0{ }^{\circ} \mathrm{C}$ prior to addition of NBD-COOH (1.29 g, $13.2 \mathrm{mmol})$. The reaction was stirred for $48 \mathrm{~h}$ at room temperature. The mixture was diluted with DCM and exacted with water three times. The organic layer was dried by $\mathrm{Na}_{2} \mathrm{SO}_{4}$ and concentrated to precipitate into methanol and water mixture (1:1 in volume ratio) three times. The product PHEA-NBD was obtained after the removal of the solvent.

Synthesis of Maleimide-terminated PPEO (Mal-PEO) side chain.

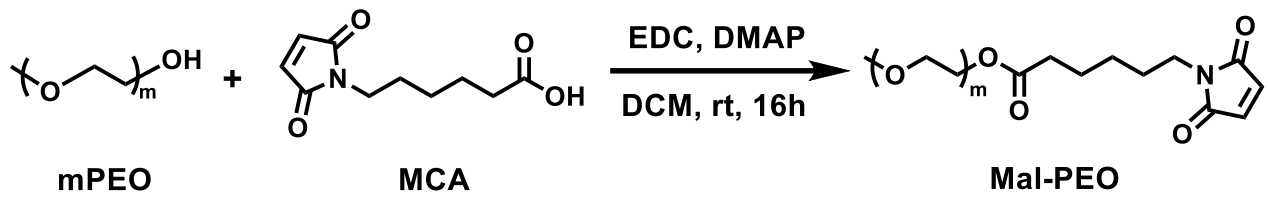

Typical procedure is as follows: To a round-bottom flask were added sequentially with $m \mathrm{PEO}_{45}(2.00$ 
g, 1.0 mmol, 1 eq), 6-Maleimidohexanoic acid (0.634 g, 3.0 mmol, 3 eq), EDC (0.554 g, 2.9 mmol, $2.9 \mathrm{eq})$, DMAP (6.11 mg, $0.05 \mathrm{mmol}, 0.05 \mathrm{eq}$ ) and $20 \mathrm{~mL}$ anhydrous DCM. The reaction mixture was allowed to be stirred at room temperature overnight. After reaction, the solvent was removed under reduced pressure and the remaining residual was purified by recrystallization from EtOH three times. The final dried product was colorless with a yield around $98 \%$.

\section{Synthesis of Maleimide-terminated RAFT agent (Fur-Mal-CBPA).}

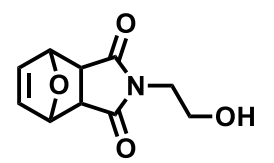

Fur-MalOH

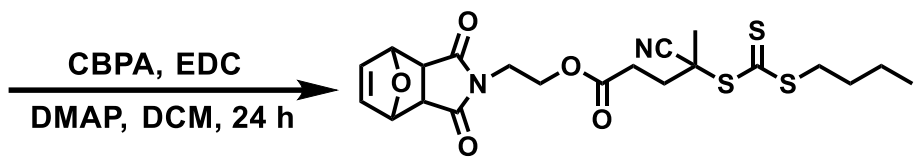

Fur-Mal-CBPA

Fur-Mal-CBPA was synthesized by the esterification reaction between Fur-Mal-OH and CBPA. FurMal-OH (0.42 g, 2.0 mmol, 1 eq.), CBPA (0.87 g, 3.0 mmol, 1.5 eq.) and DMAP (24 mg, $0.2 \mathrm{mmol}$, 0.2 eq.) were added to anhydrous DCM $(10 \mathrm{~mL})$ and cooled to $0{ }^{\circ} \mathrm{C}$. After $10 \mathrm{~min}$ of stirring in ice bath, EDC (2.57 g, $13.4 \mathrm{mmol})$ was added. The reaction was stirred for $16 \mathrm{~h}$ at room temperature. The mixture was diluted with DCM $(200 \mathrm{~mL})$ and washed with $\mathrm{HCl}(0.1 \mathrm{M})$ and brine three times. The organic layer was dried by $\mathrm{Na}_{2} \mathrm{SO}_{4}$, then filtered and concentrated to column chromatography (hexane: ethyl acetate, 2:1) to yield Fur-Mal-CBPA (0.95 g, 98\%) as a tangerine oil.

\section{Synthesis of Maleimide-terminated polymer side chains (SCs).}

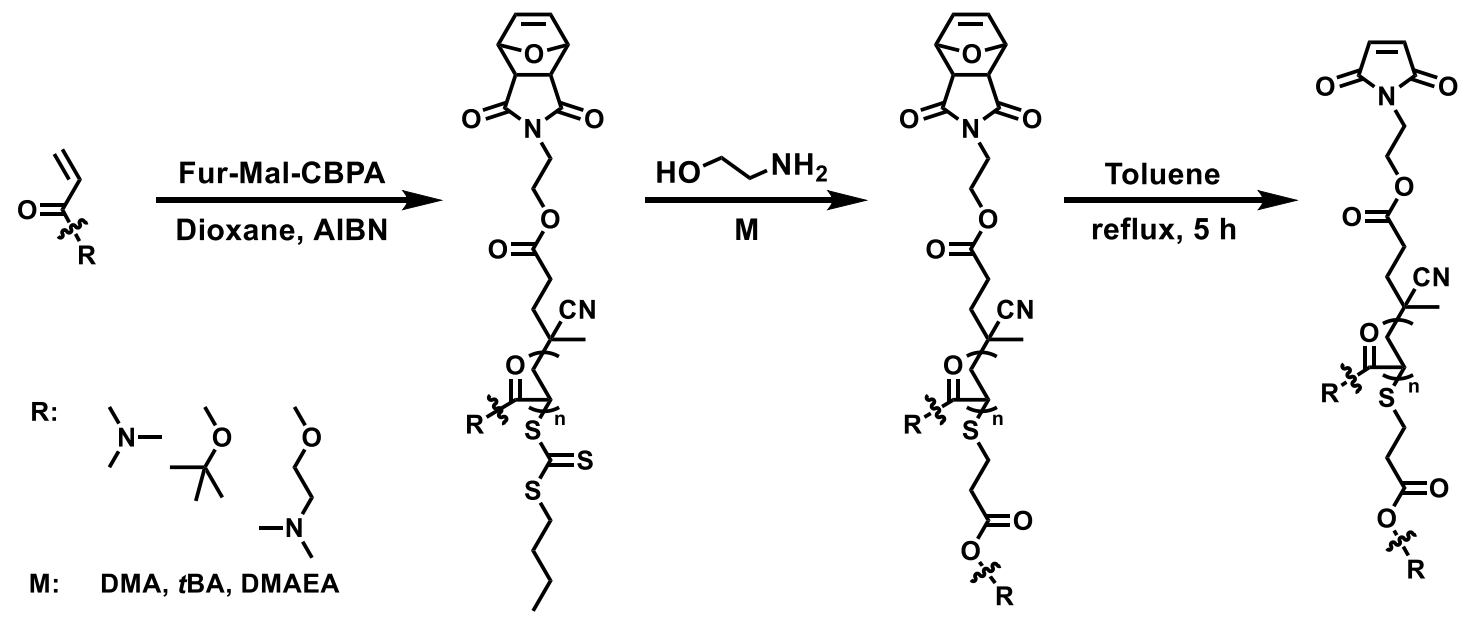

Maleimide-terminated SCs, including Mal-PtBA $32, \mathrm{Mal}_{32} \mathrm{PMA}_{28}$ and Mal-PDMAEA 21 were synthesized by a three-step reaction. Firstly, Furan protected-maleimide side chain precursors were synthesized by RAFT polymerization using furan protected-maleimide RAFT agent (Fur-Mal-CBPA) 
at feed ratio of $[\mathrm{M}]_{0}:[\text { Fur-Mal-CBPA }]_{0}:[\mathrm{AIBN}]_{0}=100: 1: 0.1$ in dioxane at $60{ }^{\circ} \mathrm{C}$. To ensure nearly complete retention of the furan protected-maleimide chain-end functionality, the polymerizations were purposely stopped at low monomer conversions (ca. $<30 \%$ ). One portion was diluted by THF or DMF for SEC measurement. Another portion was diluted by $\mathrm{CDCl}_{3}$ for the assessment of monomer conversion by ${ }^{1} \mathrm{H}$ NMR spectroscopy. After polymerization, without performing any purification. the ethanolamine (10 eq of Fur-Mal-CBPA) and a small amount of reducing agent triphenylphosphine were added to the reaction mixture directly. It can be observed that the color of the solution becomes colorless and transparent after 1 hour of reaction. After another 23 hours stirred at room temperature, the crude product was purified by precipitation. Subsequently, the purified furan protection polymers were refluxed in toluene to obtain deprotected Maleimide-terminated side chains.

\section{Synthesis of Maleimide-terminated side chain Mal-PtBA32.}

$t$ BA (2.56 g, $20.0 \mathrm{mmol})$, Fur-Mal-CBPA (96.5 mg, $0.2 \mathrm{mmol})$, AIBN (3.3 mg, $0.02 \mathrm{mmol})$ and dry dioxane (2.56 g) were added into a Schlenk tube. The mixture was degassed by three freeze-evacuatethaw cycles and the tube was sealed. The reaction was carried out at $60{ }^{\circ} \mathrm{C}$ in $3.5 \mathrm{~h}$. The mixture was cooled to room temperature and exposed to air, one portion was diluted by DMF for SEC measurement. Another portion was diluted by $\mathrm{CDCl}_{3}$ for the assessment of monomer conversion by ${ }^{1} \mathrm{H} \mathrm{NMR}$ spectroscopy. After polymerization, without performing any purification, the ethanolamine (122 mg, $2.0 \mathrm{mmol})$ and a small amount of reducing agent triphenylphosphine (1.0 mg, $0.004 \mathrm{mmol})$ were added to the reaction mixture directly. After 24 hours stirred at room temperature, the crude product was purified by precipitation into $\mathrm{MeOH} / \mathrm{H}_{2} \mathrm{O}(1: 1)$. Subsequently, Fur-Mal-PtBA (0.45 g, $\left.0.1 \mathrm{mmol}\right)$ was dissolved in $10 \mathrm{~mL}$ toluene. The solution was heated to reflux at $120^{\circ} \mathrm{C}$ for 5 hours, then cooled the solution to room temperature. The crude product was purified by rotary evaporating to afford Mal$\mathrm{P} \mathrm{BA}_{32},\left(0.44 \mathrm{~g}, M_{\mathrm{n}, \mathrm{NMR}}=4.5 \mathrm{~kg} / \mathrm{mol}, M_{\mathrm{n}, \mathrm{SEC}}=3.1 \mathrm{~kg} / \mathrm{mol}, M_{\mathrm{w}} / M_{\mathrm{n}}=1.09\right)$.

\section{Synthesis of Maleimide-terminated side chain Mal-PDMA28.}

The procedures were similar as the syntheses of Mal-P $t \mathrm{BA}_{32}$ except the use of DMA (1.98 g, 20.0 mmol). After purification, Mal-PDMA $28\left(0.31 \mathrm{~g}, M_{\mathrm{n}, \mathrm{NMR}}=3.1 \mathrm{~kg} / \mathrm{mol}, M_{\mathrm{n}, \mathrm{SEC}}=11.2 \mathrm{~kg} / \mathrm{mol}, \emptyset=\right.$ 1.13) was obtained.

\section{Synthesis of Maleimide-terminated side chain Mal-PDMAEA21.}

The procedures were similar as the syntheses of Mal-P $t \mathrm{BA}_{32}$ except the use of DMAEA (2.86 g, 20.0 
mmol). After purification, Mal-PDMAEA $21\left(0.33 \mathrm{~g}, M_{\mathrm{n}, \mathrm{NMR}}=3.3 \mathrm{~kg} / \mathrm{mol}, M_{\mathrm{n}, \mathrm{SEC}}=8.4 \mathrm{~kg} / \mathrm{mol}, \emptyset=\right.$ 1.13) was obtained.

\section{Synthesis of molecular bottlebrushes (MBBs)}

A typical procedure to prepare molecular brushes with different side chains was as follows: PHEA$\mathrm{NBD}$, maleimide-terminated side chains and $\mathrm{CHCl}_{3}$ were added into a vial. Toluene was added as an internal standard for calculation of reacted side chains by SEC measurement. One portion of the mixture was taken out to measure SEC. After that DpTz was added and the vial was capped under an atmosphere of air. Samples were taken out at different reaction times and quenched by adding norbornene for excessing DpTz.

\section{Study on the reaction condition of synthesis MBBs}

P(HEA-NBD) 105 (21.5 mg, 0.05 mmol, 1 eq of NBD group), Mal-PEO (110 mg, 0.05 mmol, 1 eq.) were added to a $5 \mathrm{~mL}$ vial, and dissolved in $2.5 \mathrm{~mL}, 1.25 \mathrm{~mL}, 0.83 \mathrm{~mL}, 0.63 \mathrm{~mL}$ of CHCl$_{3}$, respectively. Toluene $(10 \mathrm{v} / \mathrm{v} \%)$ was added as internal standard for calculation of reacted Mal-PEG by SEC measurement. One portion of the mixture was taken out to measure SEC. After that, 3,6-di-2-pyridyl1,2,4,5-tetrazine (DpTz) (29.5 mg, $0.125 \mathrm{mmol}, 2.5$ eq.) was added and the vial was capped under air and stirred at $20^{\circ} \mathrm{C}$. Take $20 \mu \mathrm{L}$ samples at regular intervals for characterization. Then, other influencing factors such as temperature and the ratio of NBD group and Mal group were probed and used the same way except control different conditions of temperature and the ratio of NBD group and Mal group separately.

\section{Synthesis of molecular bottlebrushes (MBB) with optimized condition}

The preparation of $\mathrm{P}(\mathrm{HEA}-\mathrm{g}-\mathrm{P} t \mathrm{BA})_{419} \mathrm{MBB}$ was used as an example. $\mathrm{P}(\mathrm{HEA}-\mathrm{NBD})_{419}(4.3 \mathrm{mg}, 0.01$ mmol, 1 eq of NBD group), Mal-PtBA 32 (33 mg, $0.075 \mathrm{mmol}, 1.5$ eq.) were added to a $2 \mathrm{~mL}$ vial and dissolved $0.17 \mathrm{~mL}$ of $\mathrm{CDCl}_{3}$, in which of toluene $(17 \mu \mathrm{L}, 10 \mathrm{v} / \mathrm{v} \%)$ was added as internal standard for calculation of reacted Mal-P $t \mathrm{BA}_{32}$ by SEC measurement. One portion of the mixture was taken out to measure SEC Then, DpTz (5.9 mg, $0.025 \mathrm{mmol}, 2.5$ eq.) was added and the vial was capped under air and stirred at $20^{\circ} \mathrm{C}$. After 3 hours reaction, one portion was taken to measure SEC directly. The crude product was dissolved in DCM and fractionated with cold $\mathrm{MeOH} / \mathrm{H}_{2} \mathrm{O}(1: 1)$ solution to remove the unreacted side chains. The other MBBs were prepared by similar procedure. 

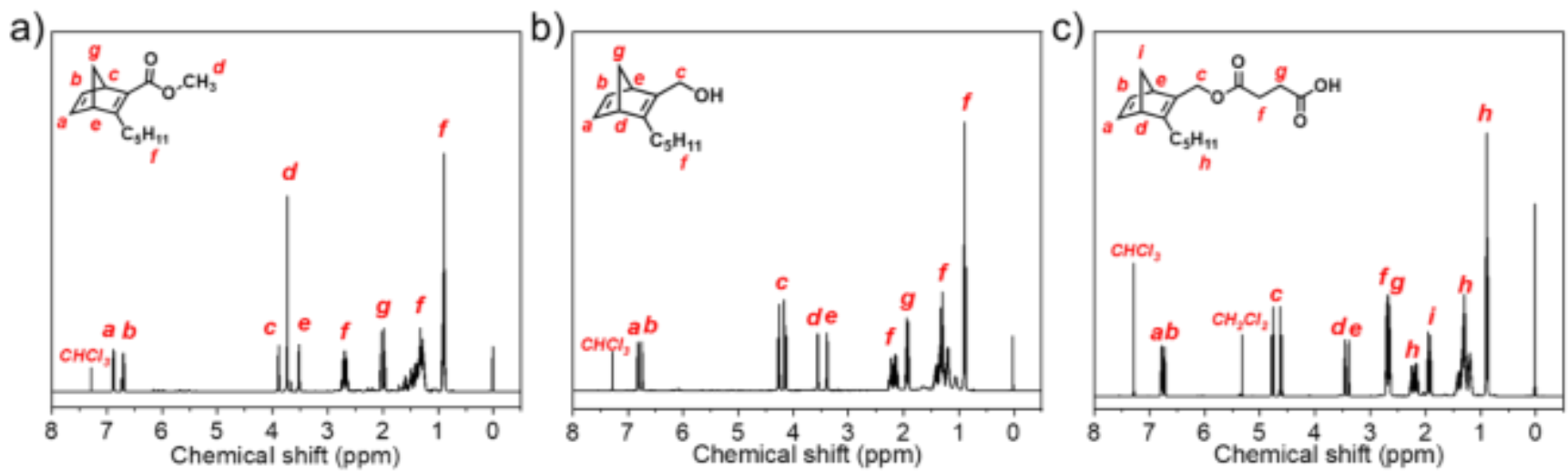

Figure S1. ${ }^{1} \mathrm{H}$ NMR spectra of a) NBD-COMe, b) NBD-OH, C) NBD-COOH in $\mathrm{CDCl}_{3}$.

a)

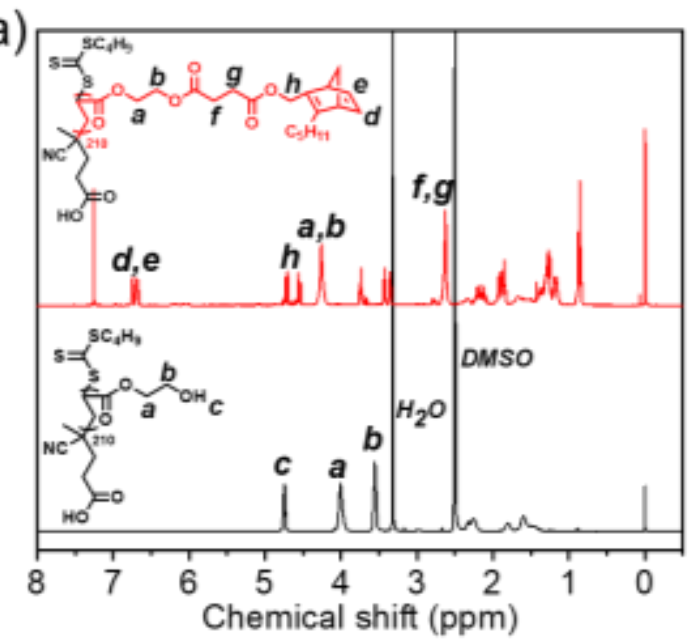

b)

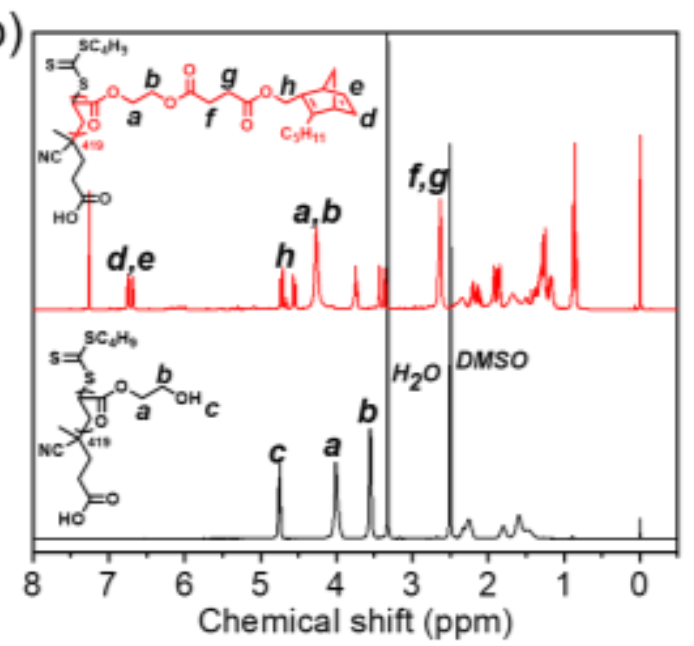

Figure S2. ${ }^{1} \mathrm{H}$ NMR spectra of PHEA $\mathrm{x}_{\mathrm{X}}$ in DMSO- $d_{6}$ and P(HEA-NBD) $\mathrm{x}$ in $\mathrm{CDCl}_{3}$ at $25 \square(\mathrm{x}=210$ and 419$)$

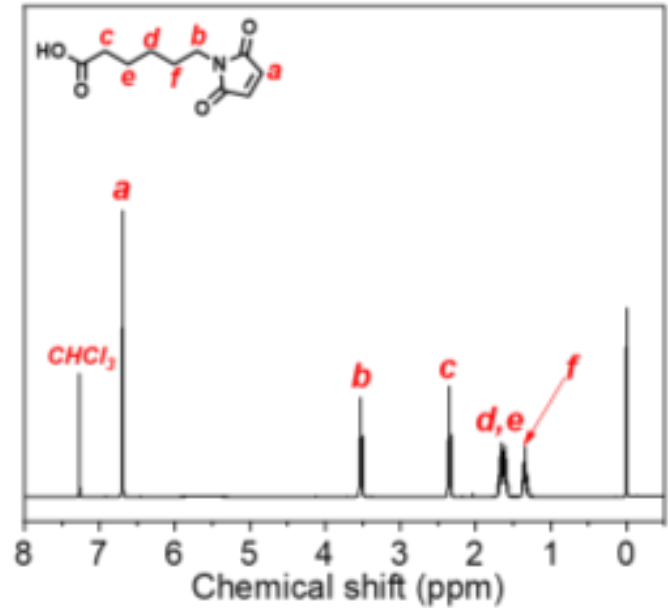

Figure S3. ${ }^{1} \mathrm{H}$ NMR spectrum of MCA in $\mathrm{CDCl}_{3}$ at $25 \square$ 
a)

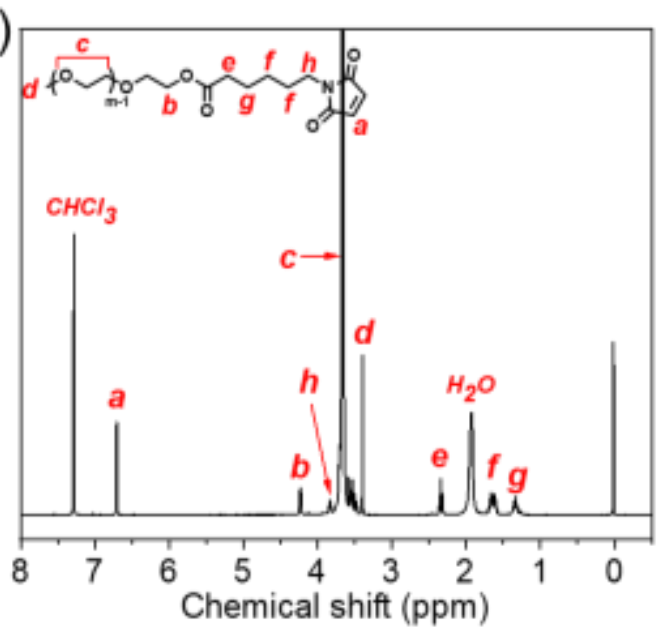

b)

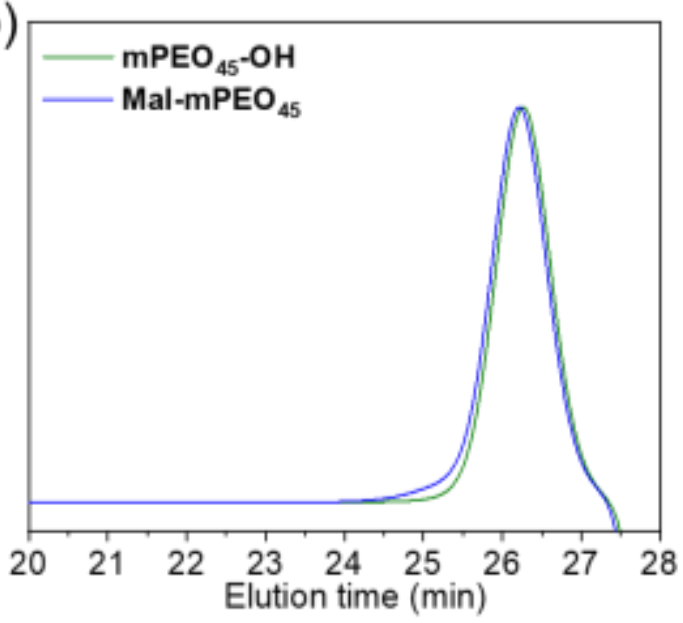

Figure S4. a) ${ }^{1} \mathrm{H}$ NMR spectra and b) SEC traces of Mal-mPEO.

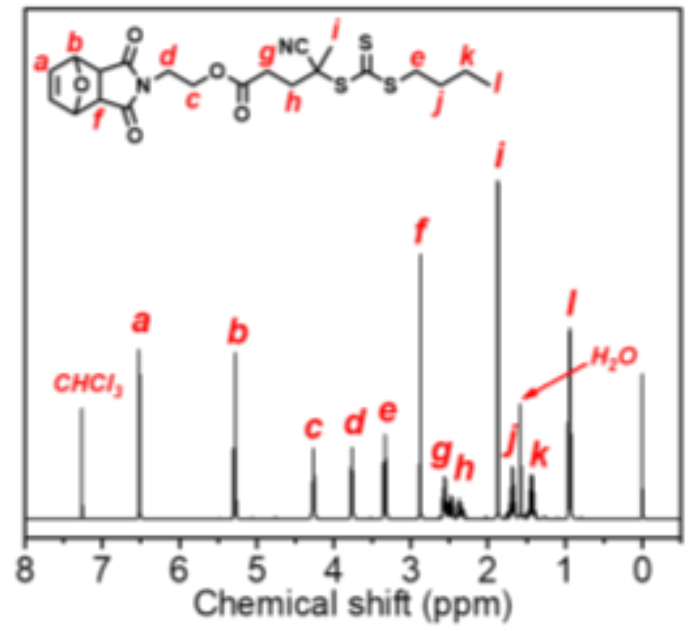

Figure S5. ${ }^{1} \mathrm{H}$ NMR spectrum of Fur-Mal-CBPA in $\mathrm{CDCl}_{3}$ at $25 \square$.

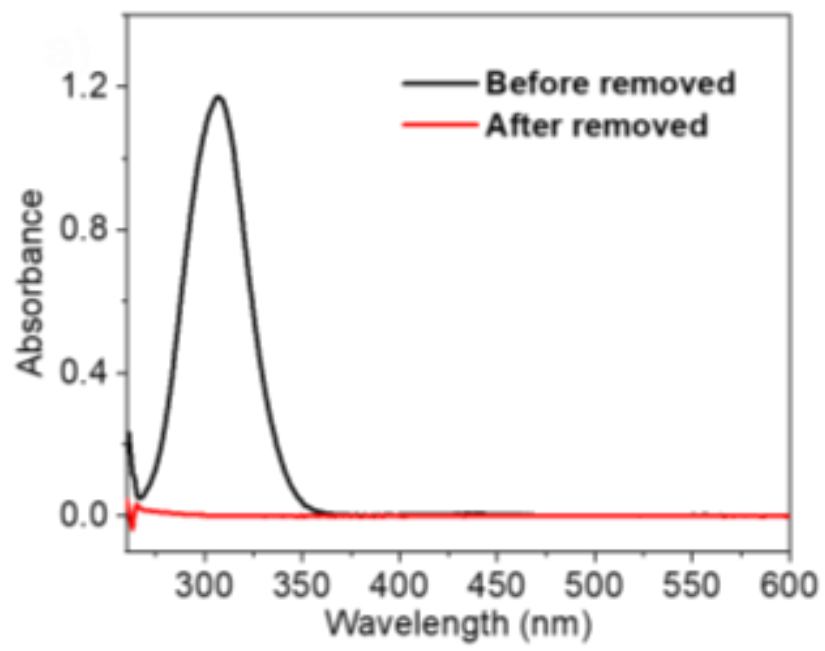

Figure S6. UV-vis spectra of Fur-Mal-P $t \mathrm{BA}_{32}$ before and after removing RAFT chain end. 
a)

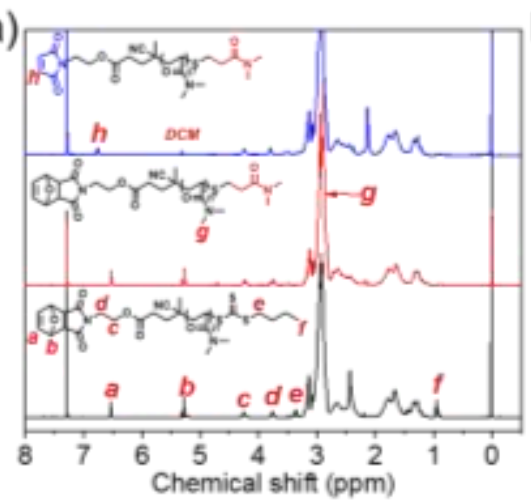

b) 1.2

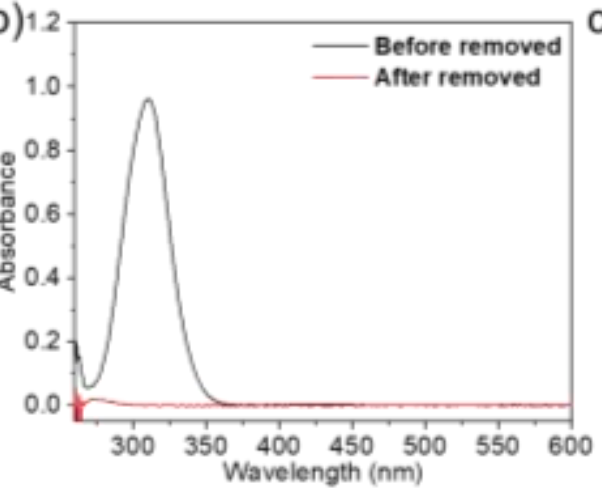

C)

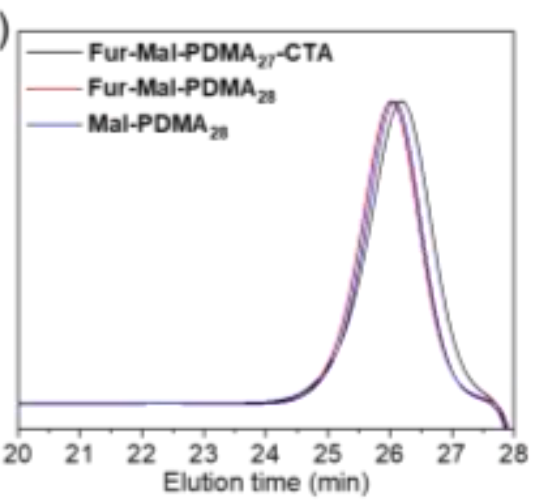

Figure S7. a) ${ }^{1} \mathrm{H}$ NMR spectra and b) UV-vis spectra, c) SEC traces of Fur-Mal-PDMA 27 , Fur-Mal-PDMA 28 and Mal-PDMA 28

a)

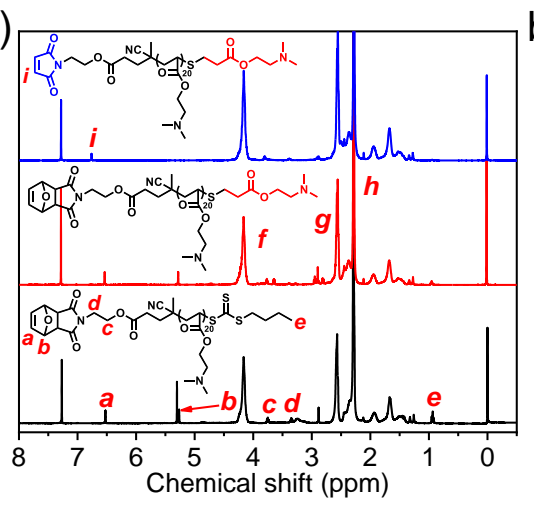

b)

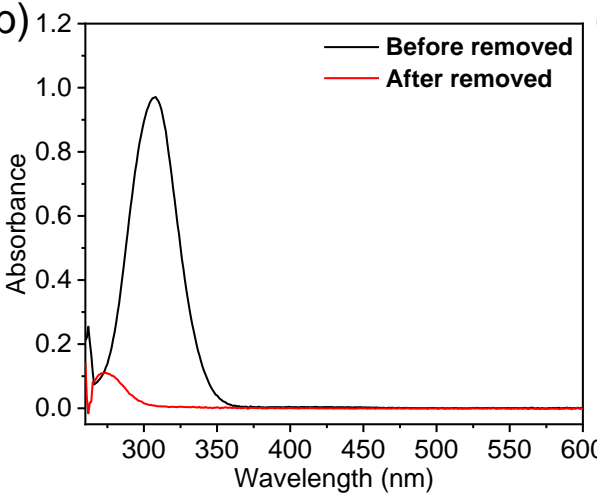

c)

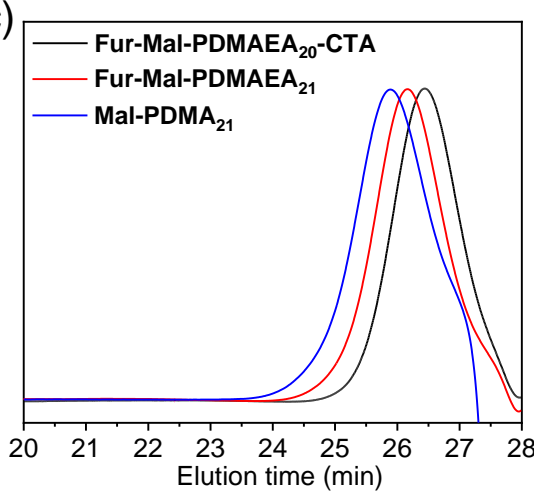

Figure S8. a) ${ }^{1} \mathrm{H}$ NMR spectra and b) UV-vis spectra, c) SEC traces of Fur-Mal-PDMAEA 20 , Fur-Mal-PDMAEA 21 and Mal-PDMAEA 21.

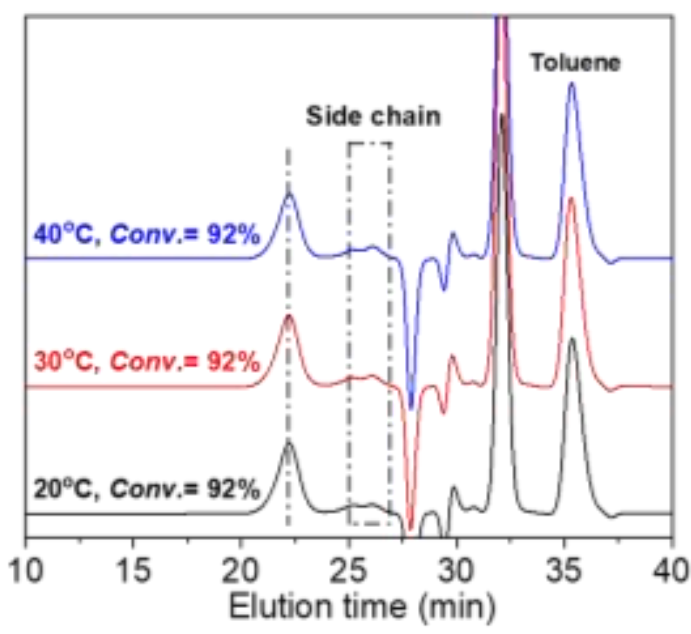

Figure S9. SEC traces of NBD-Mal click reaction between P(HEA-NBD) ${ }_{105}$ and $\mathrm{Mal}^{-\mathrm{PEO}} \mathrm{O}_{45}$ at the feed ratio of $[\mathrm{NBD}]_{0}:[\mathrm{Mal}]_{0}:[\mathrm{DpTz}]_{0}=1: 1: 2.5 \mathrm{in}_{\mathrm{CHCl}_{3}}$ under different temperature, and the $\left[\mathrm{Mal}-\mathrm{PEO}_{45}\right]_{0}=60 \mathrm{mM}$. 
a)

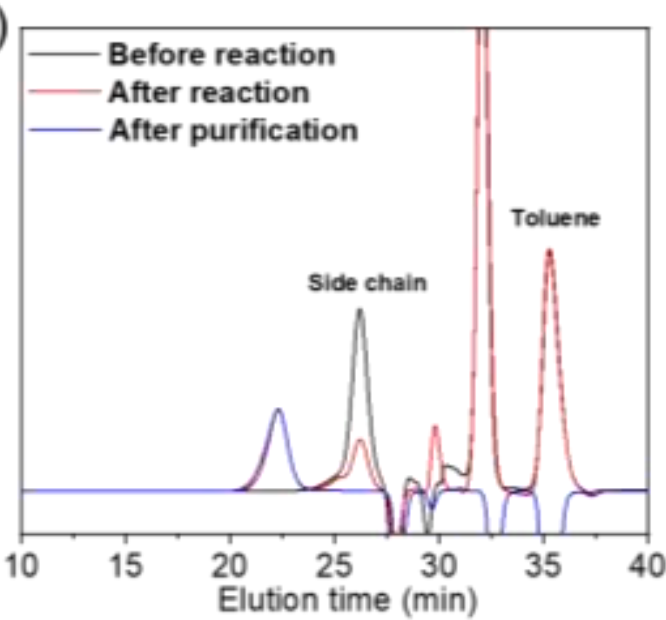

b)

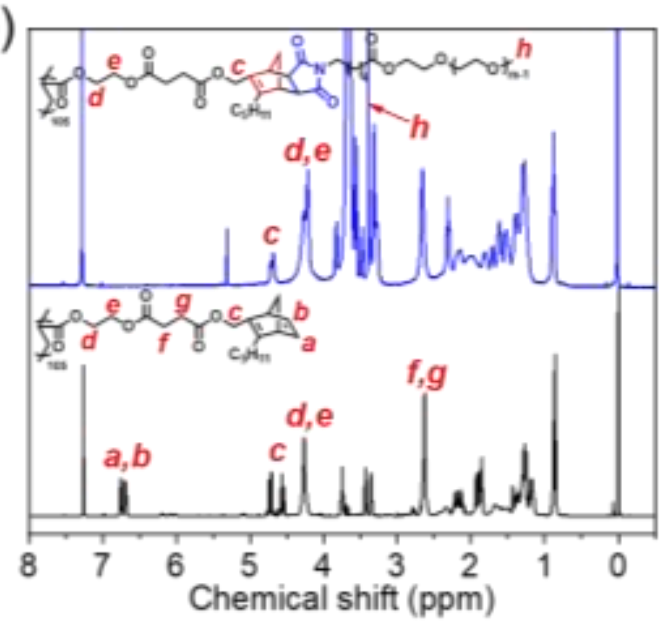

Figure S10. a) SEC traces of reaction mixture of $\mathrm{P}(\mathrm{HEA}-\mathrm{NBD})_{105}$ and $\mathrm{Mal}_{-} \mathrm{PEO}_{45}$ before (black) and after (red) NBD-Mal click reaction and the purified P(HEA-g-PEO 45$)_{105}$, b) ${ }^{1} \mathrm{H}$ NMR spectra of $\mathrm{P}(\mathrm{HEA}-\mathrm{NBD})_{105}$ and the purified $\mathrm{P}\left(\mathrm{HEA}-g-\mathrm{PEO}_{45}\right)_{105}$ in $\mathrm{CDCl}_{3}$ at $25 \square$.

a)

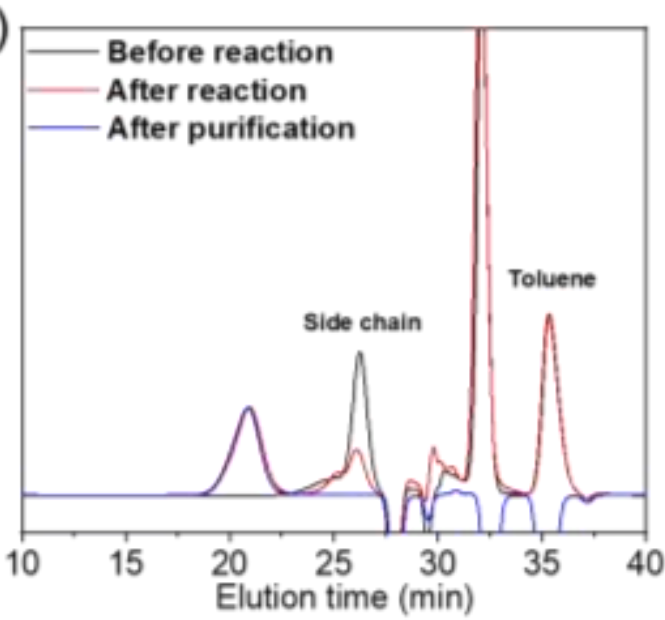

b)

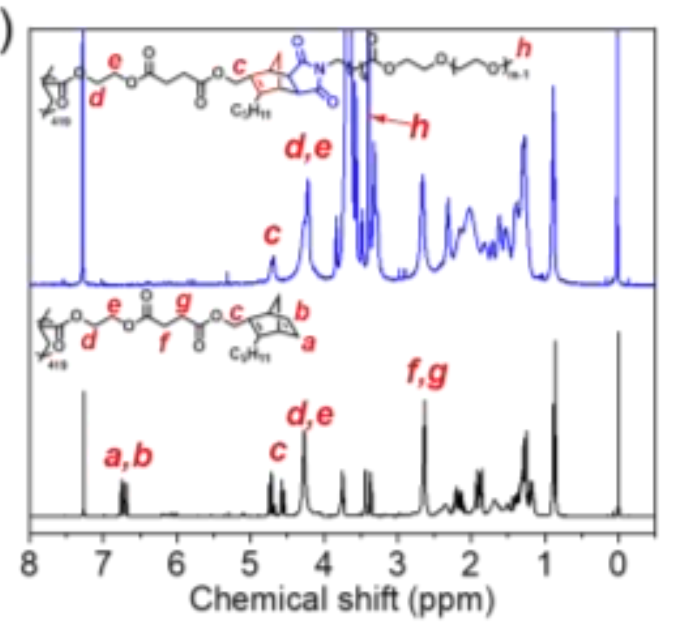

Figure S11. a) SEC traces of reaction mixture of $\mathrm{P}(\mathrm{HEA}-\mathrm{NBD})_{419}$ and $\mathrm{Mal}_{-} \mathrm{PEO}_{45}$ before (black) and after (red) NBD-Mal click reaction and the purified P(HEA-g-PEO $\left.\left.{ }_{45}\right)_{419}, b\right){ }^{1} \mathrm{H}$ NMR spectra of $\mathrm{P}(\mathrm{HEA}-\mathrm{NBD})_{419}$ and the purified $\mathrm{P}\left(\mathrm{HEA}-\mathrm{g}-\mathrm{PEO}_{45}\right)_{419}$ in $\mathrm{CDCl}_{3}$ at $25 \square$. 
a)

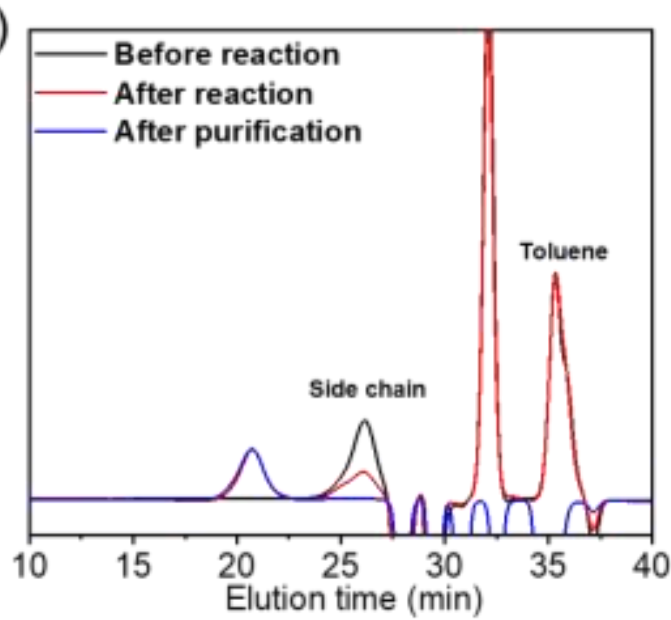

b)

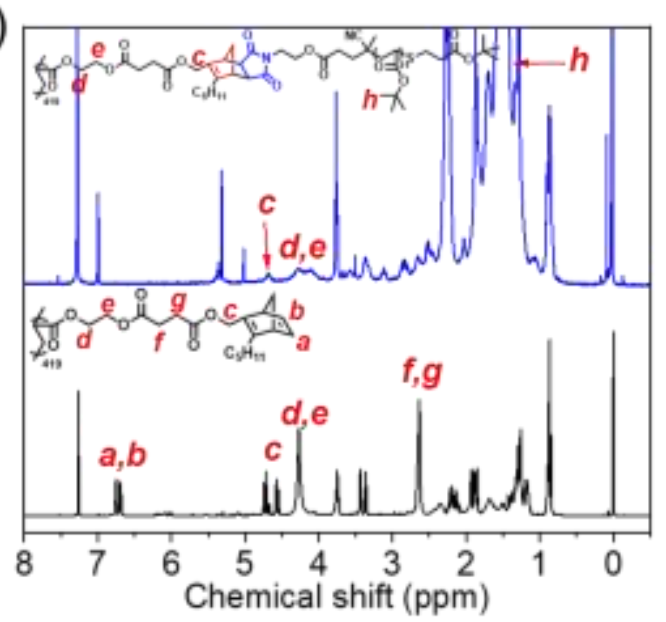

Figure S12. a) SEC traces of reaction mixture of $\mathrm{P}(\mathrm{HEA}-\mathrm{NBD})_{419}$ and Mal-P $t \mathrm{BA}_{32}$ before (black) and after (red) NBD-Mal click reaction and the purified P(HEA-g-PtBA $\left.{ }_{32}\right)_{419}$, b) ${ }^{1} \mathrm{H}$ NMR spectra of $\mathrm{P}(\mathrm{HEA}-\mathrm{NBD})_{419}$ and the purified $\mathrm{P}\left(\mathrm{HEA}-\mathrm{g}-\mathrm{PtBA}_{32}\right)_{419}$ in $\mathrm{CDCl}_{3}$ at $25 \square$.

a)

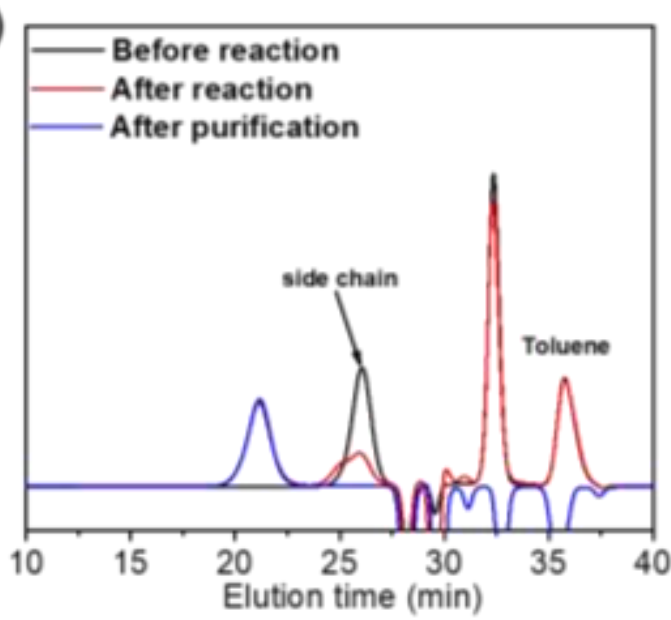

b)

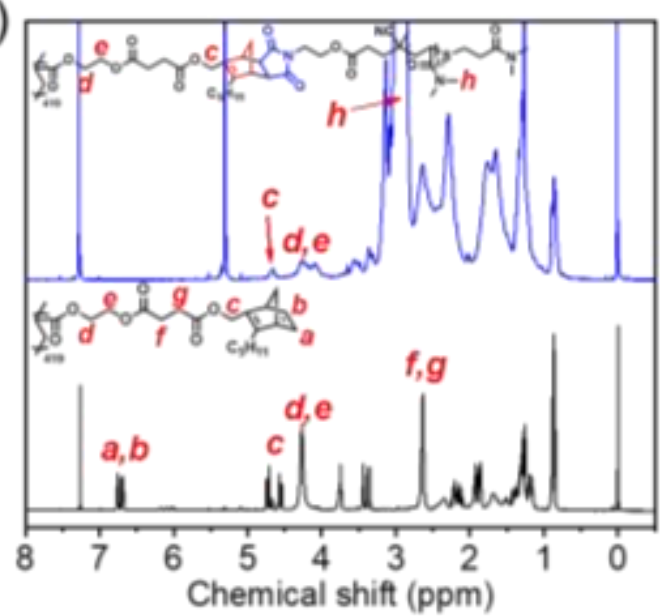

Figure S13. a) SEC traces of reaction mixture of $\mathrm{P}(\mathrm{HEA}-\mathrm{NBD})_{419}$ and Mal-PDMA 28 before (black) and after (red) NBD-Mal click reaction and the purified P(HEA-g-PDMA 28$\left.)_{419}, b\right){ }^{1} \mathrm{H}$ NMR spectra of $\mathrm{P}(\mathrm{HEA}-\mathrm{NBD})_{419}$ and the purified $\mathrm{P}\left(\mathrm{HEA}-\mathrm{g}-\mathrm{PDMA}_{28}\right)_{419}$ in $\mathrm{CDCl}_{3}$ at $25 \square$. 


\section{References}

1. Mantovani, G.; Lecolley, F.; Tao, L.; Haddleton, D. M.; Clerx, J.; Cornelissen, J. J. L.; Velonia, K., Design and Synthesis of N-Maleimido-Functionalized Hydrophilic Polymers Via Copper-Mediated Living Radical Polymerization: A Suitable Alternative to Pegylation Chemistry. J. Am. Chem. Soc. 2005, 127, 2966-2973.

2. Moad, G.; Chong, Y. K.; Postma, A.; Rizzardo, E.; Thang, S. H., Advances in Raft Polymerization: The Synthesis of Polymers with Defined End-Groups. Polymer 2005, 46, 8458-8468.

3. Figueiredo, R. M. d.; Oczipka, P.; Fröhlich, R.; Christmann, M., Synthesis of 4-Maleimidobutyric Acid and Related Maleimides. Synthesis 2008, 2008, 1316-1318.

4. St. Amant, A. H.; Discekici, E. H.; Bailey, S. J.; Zayas, M. S.; Song, J.-A.; Shankel, S. L.; Nguyen, S. N.; Bates, M. W.; Anastasaki, A.; Hawker, C. J.; Read de Alaniz, J., Norbornadienes: Robust and Scalable Building Blocks for Cascade "Click" Coupling of High Molecular Weight Polymers. J. Am. Chem. Soc. 2019, 141, 13619-13624.

5. Bailey, S. J.; Discekici, E. H.; Barbon, S. M.; Nguyen, S. N.; Hawker, C. J.; Read de Alaniz, J., Norbornadiene Chain-End Functional Polymers as Stable, Readily Available Precursors to Cyclopentadiene Derivatives. Macromolecules 2020, 53, 4917-4924. 